\title{
Assessment of Normal, Normal Variants, and Precocious Puberty in Children Referred With Signs of Early Pubertal Development to a Pediatric Endocrine Unit
}

\author{
Suna Kılınç
}

Department of Pediatric Endocrinology, University of Health Sciences Istanbul Bagcilar Training and Research Hospital, Istanbul, Turkey

\begin{abstract}
Introduction: The aim of this study was to evaluate the etiologic distribution and clinical features of children referred to a pediatric endocrinology clinic with signs of early puberty, and to compare clinical, biochemical, and anthropometric properties of the patients followed-up with the diagnosis of precocious puberty and normal variants puberty.

Methods: In this single-center study, we included children referred with signs of early puberty between July 2015 and July 2017. We retrospectively evaluated the anthropometric measurements and pubertal status of the patients. In the evaluation of patients with suspected early puberty, biochemical tests, bone age, and pelvic ultrasound were used. If indicated, a standard gonadotropin-releasing hormone stimulation test and brain magnetic resonance imaging were performed.

Results: A total of 476 children were referred for evaluation of early puberty. There were 454 (95.3\%) females. The mean age of the patients at the time of referral was $8.97 \pm 2.5$ years for girls and $9.56 \pm 0.74$ years for boys. Out of 476 children, only 139 (29.2\%) had early pubertal development, and the remaining 337 (70.8\%) had normal puberty or no puberty. Out of 139 patients, 45 (9.4\%) had precocious puberty, 59 (12.3\%) had premature thelarche, and 35 (7.3\%) had premature adrenarche. Discussion and Conclusion: Most of children referred for the evaluation of early pubertal development showed normal puberty or puberty variants. This study emphasizes the importance of a good diagnostic evaluation of these patients.

Keywords: Precocious puberty; premature adrenarche; premature thelarche; puberty.
\end{abstract}

P uberty is a transitional period from childhood to adulthood in which primary and secondary sex characteristics, sexual maturation, and reproductive ability develop $[1,2]$. As a result of the hypothalamus-pituitary-gonadal (HHG) axis activation, the onset of the pulsatile secretion of gonadotropin-releasing hormone $(\mathrm{GnRH})$ is the main mechanism that initiates puberty ${ }^{[3]}$. The onset and tempo of puberty is inherent to the individual and is managed by complex neuroendocrine-genetic mechanisms and is in- fluenced by many ethnic, nutritional, and environmental factors ${ }^{[4]}$.

Precocious puberty is defined as the breast development before the age of 8-years-old or menarche before the age of 10-year-old in girls, and is defined as the testicular volume above $4 \mathrm{~mL}$ according to the Prader orchidometer before the age of 9-years-old in boys ${ }^{[5,6]}$. Premature thelarche and premature adrenarche are considered normal variants of puberty. Premature thelarche is the occurrence of isolated

Correspondence (iletişim): Suna Kılınç, M.D. Saglik Bilimleri Universitesi Istanbul Bagcilar Egitim ve Arastirma Hastanesi,

Cocuk Endokrinolojisi Anabilim Dali, Istanbul, Turkey

Phone (Telefon): +90 2124404000 E-mail (E-posta): sunahancili@hotmail.com

Submitted Date (Başvuru Tarihi): 30.01.2019 Accepted Date (Kabul Tarihi): 11.02.2019

Copyright 2019 Haydarpaşa Numune Medical Journal

This is an open access article under the CC BY-NC license (http://creativecommons.org/licenses/by-nc/4.0/). 
breast development before the age of 8-years-old (generally before the age of 2-years-old), without any other signs of puberty. Premature adrenarche is an early pubic and/or axillary hair growth before the age of 8-years-old in girls and 9-years-old in boys without any other signs of puberty $[7,8]$.

Early pubertal disorders are common complaints for admission to pediatric outpatient clinics. Most of the applications consist of subjects with normal puberty variants. There is no need to treat these cases, as it has been determined that there is no effect on the final adult height in long-term follow-up ${ }^{[9]}$. However, their clinical follow-up is important.

In cases of early and rapidly progressive puberty, early menarche in girls and final height below the genetic potential due to an early epiphyseal closure in both genders are observed ${ }^{[1,10]}$. Early puberty has negative psychosocial effects, as well as physical effects on the child, and this causes anxiety in the parents ${ }^{[1]}$. Therefore, treatment of early puberty is a multifaceted treatment with clinical and psychological aspects. The aim of the treatment is to prevent the loss of adult height and to stop the pubertal development, as well as to prevent psychological stress and emotional problems that may be caused by precocious puberty.

The aim of this study was to determine the diagnostic distribution and clinical characteristics of patients that were referred to the endocrine outpatient clinic with signs of early pubertal development, to compare the biochemical and anthropometric properties of patients with precocious puberty and normal variant puberty, and to determine the clinical findings of patients who were followed-up and included in a therapeutic regimen.

\section{Materials and Methods}

This study approved by the Ethics Committee of University of Health Science İstanbul Bağcılar Education and Research Hospital (No: 2017.10.2.02.003). The data of the patients who referred to our pediatric endocrine clinic between July 2015 and July 2017 with the suspicion of early pubertal development were retrospectively reviewed from the patient records and patient registration forms.

The stage of puberty determined by physical examination and the height, weight, targeted height, predicted adult height (PAH), bone age, and biochemical tests were evaluated. The body weight of the patients was measured with a Seca brand digital scale, and the height of the patients standing at a neutral position was measured with a Seca brand stadiometer mounted on the wall. Body mass index (BMI) was calculated using the weight $(\mathrm{kg}) /$ height $(\mathrm{m})^{2}$ formula [11]. The height, weight and BMI standard deviation scores (SDS) were calculated. Using appropriate formulas, the targeted height was calculated for the girls as (the mother height + father height - 13)/2 and for the boys as (the mother height + father height + 13)/2. Pubertal staging was determined according to the Marshall and Tanner method ${ }^{[12,13]}$. Patients' left wrist radiograms were obtained and bone ages were determined according to the Greulich and Pyle method. The PAH of the patients older than 6-years-old was calculated using the Bayley-Pinneu method ${ }^{[14]}$.

In the evaluation of the patients with suspected early puberty hormonal tests were obtained. The levels of follicle-stimulating hormone (FSH), luteinizing hormone (LH), estradiol (E2), free-thyroxin (fT4), and thyroid stimulating hormone (TSH) , total testosterone (TT), dehydroepiandrosterone-sulfate (DHEA-S), and 17 hydroxyprogesterone (17OHP) levels were measured. LH, FSH, E2, TT, and DHEA-S levels were measured using ICMA method kits (Cobas 6000 analyzer series, Roche Diagnostics, USA). The 17-OHP level was measured by LC-MS/MS (Agilent-6460 System).

The baseline $\mathrm{LH}$ of $>0.3 \mathrm{mIU} / \mathrm{mL}$ and $\mathrm{E} 2$ of $>12 \mathrm{pg} / \mathrm{mL}$ in girls were evaluated in favor of the onset of puberty ${ }^{[1,2]}$. The dimensions of the uterus, uterine volume, endometrial thickness, corpus-to-cervix ratio, ovarian size, and ovarian follicles and their size were evaluated. On ultrasonography, the long axis of uterus ( $\geq 35 \mathrm{~mm}$ ), corpus-to-cervix ratio $(\geq 1)$, and ovarian volume ( $\geq 2 \mathrm{~mL}$ ) were evaluated in favor of the onset of puberty ${ }^{[15,16]}$.

In cases where distinction between precocious puberty and premature thelarche could not be made based on the baseline values, $\mathrm{GnRH}$-stimulation test results were used. For the GnRH-stimulation test, $2.5 \mu \mathrm{g} / \mathrm{kg}$ ( $\max 0.1 \mathrm{mg}$ ) GnRH (Gonadorelin acetate, Ferring ${ }^{\oplus}$ ) was intravenously administered. After that, blood samples were taken at 30, 60 , and 90 minutes, and the LH, FSH and E2 measurements were repeated. The stimulated LH level of $>5 \mathrm{mlU} / \mathrm{mL}$ was evaluated as pubertal response ${ }^{[17]}$.

In all male patients diagnosed with central puberty, and in all girls under 6 years of age, contrast-enhanced pituitary magnetic resonance imaging (MRI) was performed to determine etiology. MRI of the pituitary gland was performed in girls aged 6-8 years if there was only a neurological finding ${ }^{[18,19]}$. Precocious puberty was defined as an onset of breast development before the age of 8 years associated with one or more than one relevant symptoms (menstruation, growth of pubic/axillary hair, bone age older than 2 SDSs of chronological age), increases in the gonadotropin ( $\mathrm{LH}$, FSH) and/or sex steroid hormone (E2 in girls) levels, and a LH dominant response (peak LH/FSH ratio $>0.66$ ) to the 
$\mathrm{GnRH}$ test. Premature thelarche was defined as breast development before the age of 8 years without any other signs of puberty, and premature adrenarche was defined as pubic and/or axillary hair growth before the age of 8 years in girls and before the age of 9 years in boys without any other signs of puberty. Infantile pubic hair was defined as isolated pubic hair without any other findings of puberty in boys and girls $<1$ year of age.

\section{Statistical Analysis}

The data were analyzed using the Statistical Package for the Social Sciences (SPSS) (Version 17, Chicago IL, USA). Descriptive statistics for discrete and continuous variables were expressed in terms of the mean, standard deviation, median value, minimum, maximum, numbers, and percentages.

\section{Results}

Between July 2015 and July 2017, a total of 476 patients were referred to our outpatient clinic with the suspicion of early pubertal development. Twenty-two (4.6\%) patients were male, and 454 (95.3\%) of them were female. The maleto-female ratio was 20:1. The mean age at the admission was $8.97 \pm 2.5$ years for female and $9.56 \pm 0.74$ years for male patients. Only 139 (29.2\%) patients were diagnosed with early pubertal disorder. The characteristics and diagnostic distributions of the cases are presented in Table 1.

Four patients with early pubertal disorder were male, and 135 were female. The female-to-male ratio was 33:1. In males, 1 patient had precocious puberty, and 3 patients had premature adrenarche. In females, 44 (32.5\%) patients had precocious puberty, 59 (43.7\%) patients had premature thelarche, and 32 (23.7\%) patients had premature adrenarche.

The mean age of the female patients with the diagnosis of precocious puberty was $7.68 \pm 0.83$ years. The complaints started at a mean duration of $7.8 \pm 8.2$ months. Twelve patients were older than 8 years, 2 of them developed precocious puberty due to non-classical congenital adrenal hyperplasia (NCCAH), 2 of them were admitted because of menarche, and 8 of them had signs of puberty before the age of 8 , but with late applications. All patients under the age of 8 years underwent pituitary MRI. Three patients had microadenoma, 1 patient had arachnoid cyst, and 1 patient had rathke cleft cyst. In all patients under the age of 8 years, idiopathic central precocious puberty was detected. The mean age of the patients with premature thelarche was $4.4 \pm 2.61$. The complaints started at a mean duration of $8.2 \pm 10.1$ months. Thirty-seven patients (62\%) were younger than 4 years. The $\mathrm{GnRH}$ tests were performed in 17 $(28 \%)$ patients in whome clinical and laboratory findings could not differentiate among with precocious puberty. The mean age of the patients diagnosed with premature adrenarche was $6.97 \pm 0.78$ years. The complaints started at a mean duration of $6.2 \pm 9.5$ months. In terms of etiology, there were no underlying causes of premature adrenarche. The characteristics of the cases diagnosed with precocious puberty, premature thelarche, and premature adrenarche are presented in Tables 2, 3, and 4.

Table 1. Diagnostic distribution and clinical characteristics of patients that were referred with the suspicion of early pubertal development

\begin{tabular}{lcc}
\hline Diagnosis & $\mathbf{n}(\%)$ & Female/Male \\
\hline Normal puberty or no puberty & $337(70.8)$ & $319 / 18$ \\
Early pubertal disorder & $139(29.2)$ & $135 / 4$ \\
Precocious puberty & $45(9.4)$ & $44 / 1$ \\
$<8$ years & $33(6.9)$ & $32 / 1$ \\
$>8$ years & $12(2.5)$ & $12 / 0$ \\
Premature thelarche & $59(12.3)$ & $59 / 0$ \\
$<8$ years & $59(12.3)$ & $59 / 0$ \\
$>8$ years & $0(0)$ & 0 \\
Premature adrenarche & $35(7.3)$ & $32 / 3$ \\
$<8$ years & $31(6.5)$ & $28 / 3$ \\
$>8$ years & $4(0.8)$ & $4 / 0$ \\
\hline
\end{tabular}

Table 2. Clinical and biochemical characteristics of girls with precocious puberty

\begin{tabular}{|c|c|c|c|c|}
\hline & \multirow[t]{2}{*}{ Mean } & \multirow[t]{2}{*}{ SD } & \multicolumn{2}{|c|}{$\begin{array}{c}\text { Confidence } \\
\text { Interval } 95 \%\end{array}$} \\
\hline & & & Lower Limit & Upper Limit \\
\hline Age (year) & 7.68 & 0.83 & 7.43 & 7.93 \\
\hline Height (cm) & 129.7 & 8.8 & 127.0 & 132.4 \\
\hline Height SDS & 0.88 & 1.29 & 0.49 & 1.27 \\
\hline Weight (kg) & 30.6 & 7.5 & 28.3 & 32.9 \\
\hline Weight-SDS & 0.86 & 1.24 & 0.48 & 1.24 \\
\hline BMI-SDS & 0.58 & 1.10 & 0.24 & 0.91 \\
\hline $\mathrm{HA}$ & 8.47 & 1.56 & 8.00 & 8.95 \\
\hline BA & 9.75 & 1.54 & 9.28 & 10.22 \\
\hline $\mathrm{MPH}$ & 158.3 & 4.2 & 156.5 & 160.1 \\
\hline MPH-SDS & -0.71 & 0.68 & -0.99 & -0.42 \\
\hline PAH & 152.9 & 6.05 & 150.4 & 155.4 \\
\hline LH (IU/L) & 0.91 & 1.17 & 0.55 & 1.26 \\
\hline FSH (IU/L) & 2.29 & 0.94 & 2.01 & 2.58 \\
\hline $\mathrm{E} 2(\mathrm{pg} / \mathrm{mL})$ & 6.65 & 5.22 & 5.07 & 8.24 \\
\hline Peak LH $(n=32)$ & 8.99 & 6.39 & 6.60 & 11.37 \\
\hline Peak-FSH $(n=32)$ & 12.77 & 4.50 & 11.09 & 14.45 \\
\hline Pik LH/FSH & 0.75 & 0.48 & 0.67 & 0.93 \\
\hline
\end{tabular}

SD: standard deviation; SDS: standard deviation score; BMI: body mass index; HA: height age; BA: bone age; $\mathrm{MPH}$ : mid-parental height; $\mathrm{PAH}$ : predicted adult height; $\mathrm{LH}$ : luteinizing hormone; $\mathrm{FSH}$ : follicle-stimulating hormone; E2: estradiol. 
Table 3. Clinical and biochemical characteristics of girls diagnosed with premature thelarche

\begin{tabular}{|c|c|c|c|c|}
\hline & \multirow[t]{2}{*}{ Mean } & \multirow[t]{2}{*}{ SD } & \multicolumn{2}{|c|}{$\begin{array}{l}\text { Confidence } \\
\text { Interval 95\% }\end{array}$} \\
\hline & & & Lower Limit & Upper Limit \\
\hline Age (years) & 4.40 & 2.61 & 3.72 & 5.08 \\
\hline Height (cm) & 102.6 & 21.26 & 96.92 & 108.00 \\
\hline Weight (kg) & 17.98 & 6.59 & 16.26 & 19.69 \\
\hline Height SDS & -0.02 & 0.76 & -0.22 & 0.18 \\
\hline Weight-SDS & 0.27 & 0.74 & 0.08 & 0.46 \\
\hline BMI-SDS & 0.41 & 0.96 & 0.16 & 0.66 \\
\hline $\mathrm{HA}$ & 4.49 & 2.79 & 3.76 & 5.21 \\
\hline BA & 4.49 & 3.00 & 3.71 & 5.27 \\
\hline $\mathrm{MPH}$ & 158.3 & 4.87 & 151.24 & 159.77 \\
\hline MPH-SDS & -0.72 & 0.92 & -1.02 & -0.47 \\
\hline $\mathrm{PAH}(\mathrm{n}=25)$ & 156.0 & 5.04 & 150.44 & 157.43 \\
\hline LH (IU/L) & 0.52 & 0.57 & 0.37 & 0.66 \\
\hline FSH (IU/L) & 2.95 & 1.69 & 2.51 & 3.39 \\
\hline E2 $(\mathrm{pg} / \mathrm{mL})$ & 5.73 & 3.18 & 4.89 & 6.56 \\
\hline Peak LH $(n=17)$ & 3.61 & 1.20 & 3.03 & 4.18 \\
\hline Peak-FSH $(n=17)$ & 15.16 & 4.11 & 13.18 & 17.14 \\
\hline Peak LH/FSH & 0.24 & 0.09 & 0.20 & 0.29 \\
\hline
\end{tabular}

SD: standard deviation; SDS: standard deviation score; BMI: body mass index; HA: height age; BA: bone age; MPH: mid-parental height; PAH: predicted adult height; $\mathrm{LH}$ : luteinizing hormone; $\mathrm{FSH}$ : follicle-stimulating hormone; E2: estradiol.

Table 4. Clinical and biochemical characteristics of girls with the diagnosis of premature adrenarche

\begin{tabular}{|c|c|c|c|c|}
\hline & \multirow[t]{2}{*}{ Mean } & \multirow[t]{2}{*}{ SD } & \multicolumn{2}{|c|}{$\begin{array}{c}\text { Confidence } \\
\text { Interval 95\% }\end{array}$} \\
\hline & & & Lower Limit & Upper Limit \\
\hline Age & 6.97 & 0.78 & 6.69 & 7.25 \\
\hline Height (cm) & 122.27 & 5.36 & 120.33 & 124.20 \\
\hline Height SDS & 0.27 & 0.81 & -0.02 & 0.56 \\
\hline Weight (kg) & 26.96 & 5.51 & 24.98 & 28.95 \\
\hline Weight-SDS & 0.83 & 1.09 & 0.44 & 1.22 \\
\hline BMI-SDS & 0.80 & 1.13 & 0.40 & 1.21 \\
\hline $\mathrm{HA}$ & 7.25 & 0.93 & 6.91 & 7.58 \\
\hline BA & 7.90 & 1.32 & 7.42 & 8.38 \\
\hline $\mathrm{MPH}$ & 158.2 & 5.41 & 154.5 & 161.4 \\
\hline MPH-SDS & -0.72 & 0.89 & -0.97 & -0.34 \\
\hline $\mathrm{PAH}$ & 157.90 & 6.05 & 152.40 & 158.40 \\
\hline DHEA-S $(\mu \mathrm{g} / \mathrm{dL})$ & 88.42 & 38.18 & 74.65 & 102.18 \\
\hline $\mathrm{TT}(\mathrm{ng} / \mathrm{mL})$ & 0.025 & 0.00 & 0.025 & 0.025 \\
\hline 17-OHP (ng/mL) & 0.23 & 0.23 & 0.14 & 0.31 \\
\hline
\end{tabular}

SD: standard deviation; SDS: standard deviation score; BMI: body mass index; HA: height age; BA: bone age; $\mathrm{MPH}$ : mid-parental height; PAH: predicted adult height; DHEA-S: dehydroepiandrosterone-sulfate; TT: total testosterone; 17-OHP: 17-hydroxyprogesterone.
Table 5. Characteristics of patients with no early pubertal disorder

\begin{tabular}{|c|c|c|c|}
\hline Diagnosis & n (\%) & F/M & $\begin{array}{l}\text { The indication of } \\
\text { application or referral }\end{array}$ \\
\hline Lipomastia & $22(6.5)$ & $22 / 0$ & Breast development \\
\hline Infantil pubik hair & $6(1.7)$ & $2 / 4$ & Pubik hair \\
\hline Urinary tract infection & $2(0.5)$ & $2 / 0$ & Premature menarche \\
\hline $\begin{array}{l}\text { Menarche } \\
\text { (normal puberty) }\end{array}$ & $14(4.1)$ & $14 / 0$ & Premature menarche \\
\hline Obesity/overweight & $40(11.8)$ & $40 / 0$ & $\begin{array}{l}\text { Accelerated somatic } \\
\text { growth; advanced } \\
\text { bone age }\end{array}$ \\
\hline No puberty & $21(6.2)$ & $21 / 0$ & $\begin{array}{l}\text { Accelerated somatic } \\
\text { growth }\end{array}$ \\
\hline Normal puberty & $231(68.5)$ & $218 / 14$ & $\begin{array}{l}\text { Suspicion of } \\
\text { precocious puberty }\end{array}$ \\
\hline
\end{tabular}

F: female; M: male.

Among patients who were not considered as having early pubertal disorder, 22 patients were referred for breast development, but lipomastia was detected during physical examination. Two patients were referred due to premature menarche, but urinary tract infection was detected in both patients, and premature menarche was not considered. Fourteen patients presented with an early-onset menstrual period, but all were older than 10 years. Twenty-six patients who were referred for early pubertal disorder due to an accelerated somatic development were obese, and 14 patients were overweight. The characteristics of the patients with no early pubertal disorders are presented in Table 5 .

\section{Discussion}

In this single-center retrospective study 476 patients admitted/referred to our clinic with the query of early puberty but only 139 (29\%) of these patients had early pubertal disorders. Additionally, only 45 (9.4\%) of these patients had precocious puberty that requiring treatment. In this study, the number of patients that were admitted/referred with the suspicion of early puberty is very high. This shows that it is not easy to evaluate the pubertal process even if it is normal. Because of individual differences due to the effects of many factors affecting growth and puberty, evaluation of the normal course of the pubertal process requires adequate experience and sufficient social pediatric practices.

Similar studies in the literature were examined. Among them Kaplowitz et al. ${ }^{[20]}$ examined 104 patients presenting with early pubertal symptoms. Their study population mostly consisted of female cases ( $87 \%$ females vs. $13 \%$ males). Here, precocious puberty was detected in $9 \%$, pre- 
mature thelarche in $18 \%$, premature adrenarche in $46 \%$ of patients. Although the rate of female applicants was significantly higher (7:1) than the rate of male applicants in their study, the ratio of female-to-male applicants (20:1) was found to be much higher in our study. This may be related to the difference between the number of patients presenting to two studies. The rate of precocious puberty in the same study was similar to our study, but a significantly higher number of patients were diagnosed as premature adrenarche in comparison to our study. In a similar study with 449 female patients who were recently treated by Mogensen et al., ${ }^{[17]} 19.5 \%$ of the applicants were evaluated as precocious puberty, $1.3 \%$ as peripheral precocious puberty, $15 \%$ as premature thelarche, and $10 \%$ as premature adrenarche. In this study, the diagnostic rates of premature thelarche and premature adrenarche diagnosis were similar to our study. In Turkey, Eklioğlu et al. ${ }^{[21]}$ very recently examined only female patients, and detected precocious puberty in $8.3 \%$, premature thelarche in $14.6 \%$, premature adrenarche in $4.2 \%$, and premature menarche in $3.1 \%$ of their patients. The study group consisted of patients aged over 8 (69.8\%) and below 8 years of age (30.2\%). These rates are similar to those in our study. Differences in studies in terms of distribution of diagnoses may be due to diversities in the number of cases, environmental factors, socio-cultural reasons, ethnic origin, and genetic differences.

The suspicion of early pubertal disorders is one of the most common causes of admission to pediatric endocrine outpatient clinics. Most of the applications are normal variants of puberty ${ }^{[17,20,21]}$. The frequency of the normal variants of puberty differs in each community, and it is quite frequent. In the study by Atay et al. ${ }^{[22]}$ in Turkey, the prevalence rates of premature thelarche and premature adrenarche were $8.9 \%$ and $4.5 \%$, respectively, in girls under 8 years of age. Premature thelarche is especially seen between 2 and 4 years of age and is defined as isolated breast development without the acceleration of growth and progression in the bone age ${ }^{[23]}$. These cases have a normal growth tempo, bone ages are not advanced, the ovarian and uterine volumes are in prepubertal size and a FSH dominant response is received in a $\mathrm{GnRH}$ test. These patients did not have to be treated, and it was found that there were no effects on the final adult height during the long-term of follow-up. While in $60 \%$ of the cases clinical findings regress, $14 \%-19 \%$ of the cases may progress to precocious puberty [20,24-26]. Premature adrenarche is characterized by pubic hair, axillary hair, adult-type sweat, and acne as the result of an early increase in the secretion of adrenal gland androgen (especially DHEA-S) due to hitherto unknown etiologies ${ }^{[27,28]}$. In the last few years, in many publications, it has been associated with components of the metabolic syndrome, such as hypertension, dyslipidemia, and insulin resistance ${ }^{[29]}$. In our study, normal variants of puberty that did not require any treatment was detected in $19.6 \%$ of the patients. The ratio of normal variants of puberty in our study was consistent with the literature $[17,21]$.

There has been an increase in the incidence and prevalence of precocious puberty as reported in various publications. In a study conducted in Korea, the prevalence of precocious puberty was reported as 55.9 in 100.000 girls ${ }^{[30]}$. In various studies, $86 \%-92 \%$ of the cases of precocious puberty consisted of female children with a female-to-male ratio ranging from 3:1 to $23: 1^{[31]}$. However, in our study this rate was $33: 1$, and $97.2 \%$ of the cases were female patients. Our higher rate can be explained by genetic and environmental factors. The mean age at the diagnosis was 7.5 years in precocious puberty consistent with the literature ${ }^{[32]}$.

Precocious puberty is divided into three categories: gonadotropin dependent (central); gonadotropin independent (peripheral); and combined (central and peripheral)

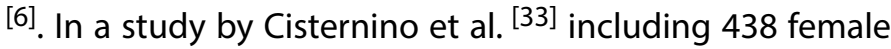
children, the patients were diagnosed as central precocious puberty $(97.7 \%)$ and peripheral precocious puberty (2.3\%). In our study, we detected NCCAH related peripheral precocious puberty in 2 (4.5\%) girls. The remaining 42 (95.4\%) patients had gonadotropin-dependent (central) precocious puberty.

Cranial MRI is recommended to rule out the intracranial pathology in patients with central precocious puberty. The prevalence of hypothalamo-pituitary lesions was found to be higher in boys with central precocious puberty $(40 \%-$ $90 \%)$, while this rate was reported to be $8 \%-33 \%$ in girls ${ }^{[34]}$. In girls whose pubertal symptoms started after 6 years of age, its prevalence is approximately $2 \%{ }^{[34]}$. In addition to the pathological findings in cranial MRI, incidental findings that do not mean any importance are also encountered ${ }^{[34]}$. These findings may cause unnecessary stress in the family and the patient, and may lead to unnecessary and potentially harmful interventions to be performed in the patient. These findings, which are not associated with central precocious puberty, have been reported to be $11 \%$ in the literature $^{[34]}$. In our study, the rate of these incidental finding was found to be $15 \%$ in patients with central precocious puberty. The most common incidental finding was pituitary microadenoma.

Rapid growth in precocious puberty, increase in the skeletal maturation rate, and progression of the bone age have 
been observed. The PAH calculated according to the bone age of the patients is especially important in terms of showing whether there will be a loss in the adult height in patients with precocious puberty. Significant losses in the predicted adult height constitute treatment indications ${ }^{[35,36]}$. In our study, all patients were evaluated according to the laboratory, clinical, and radiological findings, and a GnRH analog treatment was initiated to all patients diagnosed with central precocious puberty by considering the age of the patient, age at the time of puberty, bone age, and puberty staging.

As a conclusion, early pubertal disorder poses a greater problem for girls. Most of the presented cases have normal variants of puberty. It is important to give families more rational information not to cause exaggerated anxiety due to the fact that the cases with normal puberty that are not accurately evaluated are in excess of pathological conditions. The aim of this study was to emphasize the importance of an accurate evaluation of the patients at the diagnosis stage.

Ethics Committee Approval: This study approved by the Ethics Committee of University of Health Science İstanbul Bağcilar Education and Research Hospital (No: 2017.10.2.02.003).

Peer-review: Externally peer-reviewed.

Conflict of Interest: None declared.

Financial Disclosure: The author declared that this study received no financial support.

\section{References}

1. Antoniazzi F, Zamboni G. Central precocious puberty: current treatment options. Paediatr Drugs 2004;6:211-31. [CrossRef]

2. Mauras N. Pubertal disorders, Meet e-Professor. Handouts. ENDO 2002. San Francisco. 258-63.

3. Loomba-Albrecht LA, Styne DM. The physiology of puberty and its disorders. Pediatr Ann 2012;41:e1-9. [CrossRef]

4. Choi JH, Yoo HW. Control of puberty: genetics, endocrinology, and environment. Curr Opin Endocrinol Diabetes Obes 2013;20:62-8. [CrossRef]

5. Bordini B, Rosenfield RL. Normal pubertal development: part II: clinical aspects of puberty. Pediatr Rev 2011;32:281-92.

6. Neely EK, Crossen SS. Precocious puberty. Curr Opin Obstet Gynecol 2014;26:332-8. [CrossRef]

7. Rosenfeld RL, Cooke DW, Radovick SR. Puberty and its disorders in the female. In: Sperling MA, editor. Pediatric Endocrinology. 3rd edition. Pittsburgh: Saunders; 2008. p. 530-609. [CrossRef]

8. Lee PA, Kerrigan JR. Precocious puberty. In: Pescovitz OH, Eugster EA, editors. Pediatric Endocrinology. New York: Lippincott Williams Wilkins; 2004. p. 317-48.

9. Stanhope R. Premature thelarche: Clinical follow-up and indication of treatment. J Pediatr Endocrinol Metab 2000;13:827-30.

10. Wheeler MD. Physical changes of puberty. Endocrinol Metab
Clin North Am 1991;20:1-14. [CrossRef]

11. Bundak R, Furman A, Gunoz H, Darendeliler F, Bas F, Neyzi O. Body mass index references for Turkish children. Acta Paediatr 2006;95:194-8. [CrossRef]

12. Marshall WA, Tanner JM. Variations in the pattern of pubertal changes in boys. Arch Dis Child 1970;45:13-23. [CrossRef]

13. Marshall WA, Tanner JM. Variations in the pattern of pubertal changes in girls. Arch Dis Child 1969;44:291-303. [CrossRef]

14. Greulich WW, Pyle SI. Radiographic Atlas of Skeletal Development of the Hand and Wrist. 2nd edition. Stanford: Stanford University Press; 1966. p.185.

15. Vries L de, Horev G, Schwartz M, Phillip M. Ultrasonographic and clinical parameters for early differentiation between precocious puberty and premature thelarche. Eur J Endocrinol 2006;154:891-8. [CrossRef]

16. Haber HP, Mayer El. Ultrasound evaluation of uterine and ovarian size from birth to puberty. Pediatr Radiol 1994;24:11-3.

17. Mogensen SS, Aksglaede L, Mouritsen A, Sorensen K, Main KM, Gideon P, et al. Diagnostic work-up of 449 consecutive girls who were referred to be evaluated for precocious puberty. J Clin Endocrinol Metab 2011;96:1393-401. [CrossRef]

18. Kaplowitz PB. Do 6-8 year old girls with central precocious puberty need routine brain imaging? Int J Pediatr Endocrinol 2016;2016:9.

19. Pedicelli S, Alessio P, Scirè G, Cappa M, Cianfarani S. Routine screening by brain magnetic resonance imaging is not indicated in every girl with onset of puberty between the ages of 6 and 8 years. J Clin Endocrinol Metab 2014;99:4455-61.

20. Kaplowitz P. Clinical characteristics of 104 children referred for evaluation of precocious puberty. J Clin Endocrinol Metab 2004;89:3644-50. [CrossRef]

21. Eklioğlu BS, Atabek ME, Akyürek N, Sarıkaya E. The Etiologic Distribution and Clinical Features of Cases Presenting with the Findings of Puberty to the Pediatric Endocrinology Clinic. Turkish Journal of Pediatric Disease 2016;10:233-6.

22. Atay Z, Turan S, Guran T, Furman A, Bereket A. The prevalence and risk factors of premature thelarche and pubarche in 4- to 8-year-old girls. Acta Paediatr 2012;101:71-5. [CrossRef]

23. De Vries L, Guz-Mark A, Lazar L, Reches A, Phillip M. Premature thelarche: age at presentation affects clinical course but not clinical characteristics or risk to progress to precocious puberty. J Pediatr 2010;156:466-71. [CrossRef]

24. Volta C, Bernasconi S, Cisternino M, Buzi F, Ferzetti A, Street $M E$, et al. Isolated premature thelarche and thelarche variant: clinical and auxological follow-up of 119 girls. J Endocrinol Invest 1998;21:180-3. [CrossRef]

25. Pasquino AM, Pucarelli I, Passeri F, Segni M, Mancini MA, Municchi G. Progression of premature thelarche to central precocious puberty. J Pediatr 1995;126:11-4. [CrossRef]

26. Lee CT, Tung YC, Tsai WY. Premature thelarche in Taiwanese girls. J Pediatr Endocrinol Metab 2010;23:879-84. [CrossRef]

27. Ultriainen P, Laakso S, Liimatta J, Jaaskelainen J, Voultilainen R. Premature adrenarche-a common condition with variable presentation. Horm Res Paediatr 2015;83:221-31. [CrossRef] 
28. Voutilainen R, Jääskeläinen J. Premature adrenarche: etiology, clinical findings, and consequences. J Steroid Biochem Mol Biol 2015;145:226-36. [CrossRef]

29. Williams RM, Ward CE, Hughes IA. Premature adrenarche. Arch Dis Child 2012;97:250-4. [CrossRef]

30. Kim SH, Huh K, Won S, Lee KW, Park MJ. A Significant Increase in the Incidence of Central Precocious Puberty among Korean Girls from 2004 to 2010. PLoS One 2015;10:e0141844. [CrossRef]

31. Berberoğlu M. Precocious puberty and normal variant puberty: definition, etiology, diagnosis and current management. J Clin Res Pediatr Endocrinol 2009;1:164-74. [CrossRef]

32. Giabicani E, Allali S, Durand A, Sommet J, Couto-Silva AC, Brauner R. Presentation of 493 consecutive girls with idiopathic central precocious puberty: a single-center study. PLoS
One 2013;8:e70931. [CrossRef]

33. Cisternino M, Arrigo T, Pasquino AM, Tinelli C, Antoniazzi F, Beduschi $L$, et al. Etiology and age incidence of precocious puberty in girls: a multicentric study. J Pediatr Endocrinol Metab 2000;13:695-701. [CrossRef]

34. Mogensen SS, Aksglaede L, Mouritsen A, Sorensen K, Main $\mathrm{KM}$, Gideon $\mathrm{P}$, et al. Pathological and incidental findings on brain MRI in a single-center study of 229 consecutive girls with early or precocious puberty. PLoS One 2012;7:e29829.

35. Fuqua JS. Treatment and outcomes of precocious puberty: an update. J Clin Endocrinol Metab 2013;98:2198-207. [CrossRef]

36. Toto L, Savage MO, Antoniazzi F, Buzi F, Di Maio S, Oostdijk W, et al. Optimal therapy of pubertal disorders in precocious / early puberty. J Pediatr Endocr Metab 2001;14:985-96. 